\title{
SISTEMAS DE INFORMAÇÃO DE MARKETING EM UNIDADES DE INFORMAÇÃO EMPRESARIAL: UM MODELO PROPOSTO
}

\author{
SISTEMAS DE INFORMACIÓN EN UNIDADES DE \\ INFORMACIÓN EMPRESA DE MARKETING: UN \\ MODELO PROPUESTO
}

\author{
Ana Maria Pereira * \\ Carla Campos Pereira**
}

\begin{abstract}
RESUMO
Introdução: Propõe um modelo teórico de sistema de informação de marketing, o qual proporciona informações com atributos de qualidades, tais como: precisão, economia, flexibilidade, confiabilidade, relevância, simplicidade e verificabilidade aos decisores de organizações empresariais, com base na visão sistêmica e teorias de marketing.

Objetivo: Apresenta um modelo de sistema de informação de marketing para unidades empresariais, identificando as exigências, competências e habilidades que o mercado demanda do bibliotecário e a sua integração.

Metodologia: Revisão bibliográfica que possibilitou conhecimento teórico para propor o modelo.

Resultados: O modelo proposto é composto de cinco etapas e constituído de subsistemas que não foram identificados em sistemas de informação de marketing existentes, em que se confirma que a organização da informação é necessária para o desenvolvimento da organização

Conclusões: Identificou-se que o bibliotecário é um agente atuante, mediador de informações nos sistemas de informação de marketing em unidades empresariais, deve estar presente em todos os níveis do processo e proporcionar aos administradores uma maior credibilidade nas decisões tomadas.
\end{abstract}

Palavras-chave: Sistemas de informação. Bibliotecário - competências e habilidades. Sistemas de informação de marketing. * Doutorado em Tecnologia e Sistemas de Informação na Universidade do Minho
(UMINHO). Professora Departamento de Biblioteconomia e Gestão da Informação da
Universidade do Estado de Santa Catarina (UDESC). E-mail:
anamariapere@gmail.com
** Mestre em Ciência da Informação pela Universidade Federal de Santa Catarina
(UFSC) E-mail: carlapcpereira@gmail.com

Inf. Inf., Londrina, v. 21, n. 1, p. $324-347$, jan./abr. 2016.

http:www.uel.br/revistas/informacao/ 


\section{INTRODUÇÃO}

Os decisores, gerentes, e, sobretudo, os profissionais de marketing, deparam-se com um mercado extremamente competitivo, no qual as decisões precisam ser tomadas o mais rápida e adequadamente possíveis. É fato que no mundo atual, há uma imensa produção de informações que são assimiladas diariamente por milhares de indivíduos e que é necessário que o profissional esteja qualificado e preparado para atuar nestes diversos meios.

Para que ocorram as tomadas de decisões certas, no momento oportuno e de acordo com as necessidades da organização e para que a empresa obtenha dados concretos e lucratividade, há de se observar que o sistema de informação de marketing é um processo utilizado por uma pessoa ou empresa para registrar, organizar e processar informações sobre o mercado e seus concorrentes.

Nesse sentido, o bibliotecário, como gestor do Sistema de Informação de Marketing (SIM), tem como uma de suas habilidades, proporcionar um processo de sistematização e organização do fluxo de informações internas e externas à organização, para que os gerentes e os decisores de marketing possam habilmente tomar suas decisões.

O SIM aborda todo tipo de informação (tecnológica, arquivística, organizacional, comunitária ou para negócios), disponibilizando a informação empresarial para contribuir com a gerência, sendo, portanto, um importante recurso estratégico para o processo decisório.

Esse artigo tem por objetivo apresentar um modelo de sistema de informação de marketing para unidades empresariais, identificando as exigências, competências e habilidades que o mercado demanda do profissional bibliotecário, utiliza-se do método de pesquisa utilizado foi à revisão bibliográfica e como resultado propôs a partir do modelo apresentado demonstrar qual o papel do bibliotecário como gestor de sistema de informação de marketing em unidades de informações empresariais. 


\title{
2 O BIBLIOTECÁRIO COMO GESTOR DE INFORMAÇÃO EMPRESARIAL
}

O estudo de profissionais da informação da área da Ciência da Informação iniciou com Wassermann e Bundy (1969 apud FERREIRA, 2005, p. 17) nos Estados Unidos, e ao longo dos anos a Federação Internacional de Informação de Documentação (FID) está pesquisando sobre a atuação desses profissionais. De acordo com a vice-presidente da Federação Margarita Almada de Ascencio (apud ARRUD; MARTELETO; SOUZA, 2000, p. 19).

\begin{abstract}
Nenhum profissional da atualidade tem condições de reunir todas as habilidades, conhecimentos e competências necessários para interagir e equacionar os problemas decorrentes dos fluxos de informação e conhecimento. Para resolvê-los é necessária a formação de equipes interdisciplinares em todos os níveis e processos: estratégico, gerenciais e operatórios.
\end{abstract}

Os profissionais da informação encontram nas organizações, em geral, sistemas de informações que têm por finalidade fornecer informações aos decisores. Esses profissionais são formados por um grupo bem diversificado e que segundo Ferreira (2005, p. 14) "compreende os arquivistas, documentalistas, gerentes de bases de dados, consultores de informação, profissionais da comunicação, analista de informação" entre outros. Contudo, a sociedade contemporânea demanda, de profissionais cujas competências são intrínsecas ao bibliotecário e que são adquiridas durante sua vida acadêmica e profissional. Estas são, segundo Piggott (1996, p. 1), "Comunicação, Informática, Ciência da Informação", acrescentamos a este "trio" a Gestão da Informação.

Com o desenvolvimento econômico e a quantia de informação gerada diariamente, evidencia-se o bibliotecário como um agente mediador do processo informacional, que possui qualidades e habilidades e capacidades para integrar equipes interdisciplinares 
Ana Maria Pereira, Carla Campos Pereira

Sistemas de informação de marketing em unidades de informação empresarial: um modelo proposto

fundamentais para o hábil processamento e disseminação da informação.

Ratifica-se o bibliotecário como agente desse processo quando Silva et. al. $(2013$, p. 3$)$ cita que:

Os profissionais da informação que tem seu objeto de trabalho em comum, a informação, em processos que envolvem busca, armazenamento e disseminação para um usuário final, seja ele de uma única pessoa até uma organização, podem trabalhar de maneira colaborativa de forma a atingir um nível de excelência diferenciada, dando ao produto final um valor agregado e a empresa vantagem competitiva.

As competências e habilidades específicas do bibliotecário segundo o Parecer CNE/CES 492/2001 (BRASIL, 2001, p. 32) são:

Interagir e agregar valor nos processos de geração, transferência e uso da informação, em todo e qualquer ambiente;

Criticar, investigar, propor, planejar, executar e avaliar recursos e produtos de informação;

Trabalhar com fontes de informação de qualquer natureza;

Processar a informação registrada em diferentes tipos de suporte, mediante a aplicação de conhecimentos teóricos e práticos de coleta, processamento, armazenamento e difusão da informação;

Realizar pesquisas relativas a produtos, processamento, transferência e uso da informação.

Observando-se as competências e habilidades citadas no Parecer, verifica-se como o bibliotecário pode e deve atuar em unidades de informações nos diversos setores. Rezende (2002, p. 1) afirma que:

A evolução das características e as necessidades dos diferentes usuários de informação em empresas vêm determinando, ao longo do tempo, não apenas a criação de diversos tipos de sistemas de informação para atendê-los, como também uma constante adaptação do perfil de formação acadêmica e de atuação dos profissionais da informação. Ao primeiro e tradicional modelo de biblioteca técnica de empresa,

Inf. Inf., Londrina, v. 21, n. 1, p. $324-347$, jan./abr. 2016. 
seguiram-se os centros de documentação, os centros de informação, as bibliotecas virtuais, os sistemas de inteligência competitiva e, atualmente, os programas de gestão do conhecimento. O reconhecimento da importância estratégica da administração do conhecimento e do capital intelectual das empresas configura-se como a mais recente fase de evolução na gestão da informação. Os diferentes modelos de sistemas de informação para empresas já surgidos, apesar de distintos, não se excluem e convivem, ainda que parcela significativa dos profissionais da informação não venha acompanhando e se adaptando a essa evolução e esteja perdendo espaço de atuação para profissionais de outras áreas.

De acordo com Rezende (2002) e com o Parecer CNE/CES 492/2001(BRASIL, 2001, p. 32), os bibliotecários estão cada vez mais aptos a reconhecer, atuar e gerenciar os sistemas de informação, bem como, os sistemas de informação de marketing organizacional.

Ferreira (2005, p. 21) considera que as habilidades do bibliotecário demandadas pelo mercado são:

Conhecimento do ambiente de negócios da informação;

Capacidade de trabalhar em grupo;

Distinção e localização de informações relevantes e relevância nas informações;

Domínio na utilização de equipamentos eletrônicos e na operação de sistemas ou softwares específicos;

Conhecimento de base de dados;

Familiaridade na administração de info-business;

Embasamento teórico e prático sobre o funcionamento das organizações virtuais de informação;

Domínio da lógica dos sistemas de indexação e webfinders;

Excelência na comunicação oral e escrita;

Conhecimento da infra-estrutura e serviços de informação;

Flexibilidade e polivalência;

Atualização profissional constante;

Capacidade de entender e gerenciar episódios de diferentes naturezas e aplicações;

Habilidade na identificação de clientes e fornecedores; e

Habilidade na identificação de parceiros. 
Assim, compete ao bibliotecário desenvolver estas habilidades e colocá-las em prática, e sua atualização contínua é fundamental para sua permanência neste mercado tão competitivo.

Deste modo, configura-se o Bibliotecário nas organizações empresariais como um gestor de sistemas de informação com características, habilidades e competências específicas à área. O Bibliotecário de Sistemas (SILVA, 2005) é o responsável pelo gerenciamento de sistemas da organização, sendo o responsável pelo acesso à informação pelos clientes internos. Mais do que inserir dados e organizar a informação contida na organização em uma tela de computador, o seu trabalho é tão essencial quanto o do administrador na gestão e compreendem-se como atividades de rotina do bibliotecário de sistemas:

Envolver-se no planejamento e seleção de sistemas computacionais para uso de unidades de informação; Estabelecer um canal de comunicação entre o fornecedor de software e a organização para assuntos técnicos, relacionados à informática;

Executar tarefas para a manutenção e o bom funcionamento do sistema;

Configurar e parametrizar/customizar as opções do sistema, conforme os serviços oferecidos pela organização;

Supervisionar a alteração das páginas Web (ordem e conteúdos das telas, design);

Geração de documentos e relatórios (HTML, PDF, etc.); Lidar com o fluxo de informações no sistema, manipulando dados para fins estatísticos;

Prestar suporte em atividades de manutenção e desenvolvimento dos sistemas e subsistemas. (SILVA, 2005, p. 30).

As atividades do bibliotecário de sistemas descritas por Silva (2005), em conjunto com as funções do profissional de marketing, citadas por Mattar (1986, p. 2), configuram-se em quatro áreas de atividades: "planejamento; organização; direção; e controle" de marketing que se interligam proporcionando maior eficiência na gerência do sistema de informação de marketing. 
Um SIM é um processo no qual se monitora, registra, organiza e processa informações sobre 0 ambiente externo e interno em que a unidade de informação está inserida. A partir deste enunciado e das práticas biblioteconômicas verifica-se que as características do Bibliotecário são favoráveis ao gerenciamento de sistemas de informação em marketing.

Segundo Mattar (1996), compreende-se que os bibliotecários têm, conforme suas funções, competências e habilidades para atuar como gestor de sistemas de informação de marketing, integrando assim a equipe interdisciplinar do SIM, sempre atento à transformação do ambiente interno e externo da organização relacionada ao mercado econômico.

O bibliotecário como gestor de um SIM deve observar o ambiente organizacional em que está inserido, pois deve proporcionar informações de qualidades aos decisores. Neste sentido, o bibliotecário tem as características e capacidades adequadas para gerir um sistema de informação e um ciclo informacional com mais agilidade e precisão.

Devido ao grande número de informações existentes, o mercado requisita profissionais capacitados para gerir, administrar as informações de forma dinâmica, que sejam receptivos, persistentes e dispostos a mediar o fluxo da informação e suas funções para que possibilitem ao decisor a tomada de decisão num mercado tão competitivo. Nesse contexto, atualmente, o bibliotecário está desenvolvendo um perfil empreendedor, pois além de estar apto a qualificar e mediar à informação entre a fonte e o cliente, possui competências para gerir os SIM.

Desta forma, Cunha (2000, p. 1) aborda que:

Em primeiro lugar, porque é preciso nos convencer que, como bibliotecários, fazemos parte de um grupo cada vez mais diversificado de profissionais que lidam com a informação, entre eles os arquivistas, os documentalistas, os gerentes de bases de dados, os consultores de informação, e os profissionais da 
comunicação, entre outros. Em segundo lugar, porque o trato com a informação na sociedade contemporânea requer a atuação de profissionais com grande variedade de competências. Alguns autores americanos como Piggot (1996) definem esta área com três cês Comunicação, Computação e Ciência da informação. Nós acrescentaríamos a Gestão da Informação a este trio. A combinação destas quatro áreas significa serviços de informação gerenciados, com suporte tecnológico, analisados e disseminados de forma eficaz.

Nesse sentido, verificou-se que o bibliotecário por sua formação acadêmica pode ser eficaz no gerenciamento do SIM e na gestão de informações organizacionais, visto que este profissional detém conhecimentos e técnicas que facilitam e aprimoram este sistema.

Ao analisar as capacidades de habilidades do bibliotecário como gestor da informação, e após estudos realizados, este artigo apresenta na seção Modelo de Sistema de Informação de Marketing (MSIM) um modelo proposto para a gestão da informação em SIM, e tem como objetivo identificar o bibliotecário como um agente atuante e mediador de informações como coadjuvante em todos os níveis do processo do (SIM) para que possa proporcionar aos gestores maior credibilidade e agilidade nas decisões tomadas.

\section{SISTEMA DE INFORMAÇÃO DE MARKETING (SIM)}

O marketing está se solidificando desde meados do século passado, sendo reconhecido por organizações e gestores como um processo que auxilia aos decisores.

Para American Marketing Association (AMA) o Marketing pode ser considerado com uma atividade, conjunto de instituições e processos para criar, comunicar, entregar e trocar ofertas que tenham valor para os clientes, parceiros e sociedade em geral. (AMERICAN MARKETING ASSOCIATION, 2013, tradução nossa).

O sistema de informação de marketing (SIM) desenvolve importantes insumos ao desenvolvimento empresarial. 
O termo foi denominado por Kotler (1968 apud MATTAR, 1986) que identificou esta atividade como Marketing InformationandAnalysis Center. No entanto, em suas obras posteriores adotou o termo Marketing Information Systems (MKIS) ou Sistemas de Informação de Marketing.

Os gerentes de marketing processam, planejam e executam as informações das organizações, estabelecendo preços, promoção e distribuição de ideias, produtos e serviços, com o objetivo de satisfazer as metas individuais e organizacionais. É uma função que agrega valor para o cliente e gera vantagem competitiva para a organização, por meio da gestão estratégica do marketing e da informação.

O marketing é um instrumento de gestão importantíssimo nas organizações, tanto no âmbito interno como externo e Amaral (2007, p. 19) afirma que o marketing:

[...] não é, nem significa simplesmente vender, tampouco se limita apenas à divulgação ou à propaganda. Suas ações não começam com os produtos e os serviços, começam com o cliente. Marketing não é somente fazer dinheiro, nem suas técnicas podem ser utilizadas apenas pelas organizações que recebem dinheiro pelos seus produtos e pelos seus serviços. Marketing é bom senso aplicado ao negócio de provisão de produtos e serviços aos clientes, a partir da identificação das necessidades desses clientes e do planejamento das atividades a serem desenvolvidas, que resultarão nos produtos e/ou serviços para atendê-los. É focalizar o que se faz, para quem se faz e porque se faz. Daí a relação inseparável de marketing e planejamento. É a filosofia, conceituação ou orientação para administrar ou gerir, que deve estar incorporada a todo tipo de planejamento do negócio, seja ele qual for.

Observando-se o conceito de Amaral (2007), pode-se inferir que se trata de uma 'mescla' de marketing e marketing social, que segundo Kotler e Roberto (1992, p. 25) 
[...] é uma estratégia de mudança de comportamento. Ele combina os melhores elementos das abordagens tradicionais da mudança social num esquema integrado de planejamento e ação, além de aproveitar os avanços tecnológicos das comunicações e na capacidade do marketing.

O marketing social é atualmente aplicado em todos os setores da administração, tanto governamental, quanto não-governamental, tanto quanto lucrativas ou não. Seu conceito é muito similar ao marketing tradicional e Kozel Junior (1997, p. 214) afirma que:

O marketing social cria e administra todo o processo, cujas ações e resultados passam a construir valores que se agregam aos produtos. O assistencialismo, mesmo se efetuado de forma sistemática, pouco agrega ao conceito da empresa, pois ela não gerencia nem detém a autoria e o controle do processo.

Para reafirmar que o marketing social está se tornando, cada vez mais, uma importante ferramenta gerencial a International Social Marketing Association (ISMA) (INTERNATIONAL SOCIAL MARKETING ASSOCIATION, 2013) assegura que o marketing social visa desenvolver e integrar conceitos comerciais com outras abordagens para influenciar comportamentos, nos quais os indivíduos e as comunidades se beneficiem e como consequência um maior bem social.

Procura integrar percepções de pesquisas, melhores práticas, teoria, público e parceria, para informar a entrega da concorrência sensível a segmentados programas de mudanças sociais que são eficazes, eficientes, equitativas e sustentáveis. (INTERNATIONAL SOCIAL MARKETING ASSOCIATION, 2013, p. 1, tradução nossa).

A partir das definições abordadas na literatura, verificou-se que as práticas de marketing e marketing social contribuíram com o desenvolvimento socioeconômico, e que por sua vez é uma das competências que o bibliotecário deve desenvolver e aprimorar. 
Com base em Amaral (2011) ressalta-se que

\begin{abstract}
É notório o impacto da globalização, da digitalização, da conectividade, da personalização, da velocidade, dos relacionamentos com os clientes, dos serviços de autoatendimento, da comunicação de marketing, dos novos sistemas de gestão, do atendimento ao cliente, principalmente depois do surgimento da internet. Existe uma série de novos temas e uma mudança de paradigma que reflete tanto a natureza mutável dos serviços de informação quanto às perspectivas teóricas e práticas do marketing. (AMARAL, 2011 p. 91).
\end{abstract}

Deste modo, ao relacionar a tecnologia às definições $\mathrm{e}$ observando os pontos análogos de um sistema de informação de marketing é possível compreender que o SIM é um sistema de interface entre pessoas que se utilizam de equipamentos para obter informações complacentes, por meio de tratamento de dados, provenientes da pesquisa de marketing, cuja execução e coleta de dados são realizadas de forma metódica e planejada, e deste modo os dados após processados, formatados e transformados em informações, geraram produtos como, por exemplo, os relatórios para os decisores.

Para realizar a análise, planejamento, implementação e controle das responsabilidades do marketing, os gerentes de marketing necessitam de informações e este é o principal papel do SIM: avaliar as necessidades de informações dos decisores e distribuí-las de maneira oportuna.

Nesse contexto, o conceito de sistema de informação de marketing (SIM) abordado no presente artigo se refere à coleta, tratamento, organização, processamento, disseminação, distribuição de idéias, produtos e serviços de dados e informações com o objetivo de proporcionar suporte ao processo de tomada de decisão. 


\section{MODELO DE SISTEMA DE INFORMAÇÃO DE MARKETING (MSIM)}

O modelo proposto no presente artigo tem sua fundamentação teórica com base nos atributos da informação, que tem como características ser: precisa, completa, econômica, flexível, confiável, relevante, simples, pontual, verificável, acessível, segura (STAIR; REYNOLDS, 1999, p. 6) bem como apresenta suas bases teóricas nas tecnologias da informação com o objetivo de apoiar os decisores, em suas tomadas de decisão.

Para Stair e Reynolds (1999), um modelo é uma abstração ou uma aproximação usada para representar a realidade, que nos habilita a explorar e melhor entender as situações do mundo real. Segundo os mesmos autores, "existem vários tipos de modelos, sendo os principais: narrativos, físicos, esquemáticos e os matemáticos [...]" após estudos realizados na revisão de literatura, propôs-se um "modelo esquemático, que é uma representação gráfica da realidade" (STAIR; REYNOLDS, 1999, p. 11).

(O modelo está fundamentado sobre tripé: i) Sistemas, ii) Informação e iii) marketing.

i) Sistema é o conjunto de elementos que interligados interagem formando um todo organizado, de acordo com Stair e Reynolds (1999, p. 7): "Um sistema é um conjunto de elementos ou componentes que interagem para cumprir metas. Os elementos por si próprios e os relacionamentos entre eles determinam como um sistema funciona." Os sistemas têm entradas, mecanismos de processamento, saídas e realimentação.

ii) Informação é uma coleção de fatos organizados de modo que adquirem um valor adicional além do valor dos próprios fatos (STAIR; REYNOLDS, 1999). O que o torna um sistema interagente, o qual proporciona informações valiosas aos decisores.

iii) Marketing segundo Jamil (2001, p. 54) é: 
Um conjunto integrado de disciplinas, estudo e mecanismos de projetos estratégicos e sistêmicos, usados para obtenção de lucro em uma oportunidade identificada de negócio, procurando satisfazer e encantar o cliente, de tal forma que a relação de fornecimento de produto ou serviço perdure, mantendo a 'fidelidade' deste cliente para com o fornecedor.

Autores como Li, MCleod e Rogers (2001); Kotler e Armstrong (2000); Semenik e Bamossy (1996); e Lambin (2000) foram importantes na formulação de modelos para SIM.

Com base nos modelos existentes, propôs-se um modelo de processos de Sistema de Informação de Marketing, cujos produtos têm como características satisfazer as necessidades dos decisores, obtendo por meio destes processos, informações tais como: mercado potencial, imagem organizacional, características de mercado, tendências, segmentação e distribuição e destacando a presença do bibliotecário como responsável pelo mesmo, integrando uma equipe interdisciplinar.

O modelo proposto é composto de cinco etapas: i) sistema de informação de marketing; ii) subsistema de pesquisa de marketing; iii) subsistema de análise; iv) subsistema de tratamento da informação; v) subsistema de disseminação seletiva da informação (DSI) (Figura 1).

Figura 1 - Modelo de sistemas de informação de Marketing

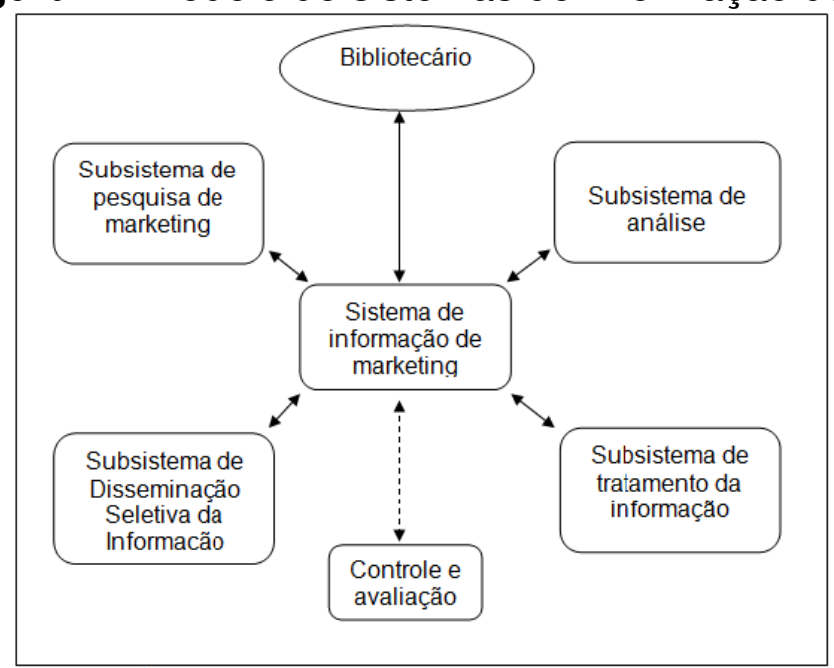

Fonte: Elaborado pelas autoras. 
A seguir são descritos cada etapa do Sistema de Informação de Marketing e os subsistemas propostos com base nos modelos estudados na literatura.

\section{- Sistema de informação de marketing}

O Sistema de Informação em Marketing (SIM) deve ser definido no planejamento estratégico de marketing da organização como a figura central do sistema, responsável por todo o processo de coleta, qualificação, análise, disseminação e armazenamento das informações aos decisores, bem como pela vistoria, coordenação e definição dos propósitos e metas a alcançar.

Sistemas de Informação de Marketing (SIM) - tem o objetivo de reunir, avaliar e distribuir as informações aos decisores. Neste contexto, o bibliotecário - considerado como o mediador - possui competências e habilidades para a gestão e transmissão de informações.

Neste contexto, o sistema proposto tem como objetivo principal proporcionar informações com qualidades e procedência para que os decisores possam direcionar os produtos e serviços para o mercado emergente. É necessário que o SIM seja planejado, analisado, implantado, avaliado, implementado e supervisionado por uma equipe interdisciplinar que inclua a presença do bibliotecário que possua habilidades e capacidades de gerir informações, que visualize este sistema sob a óptica sistêmica, que entenda e compreenda os ciclos da informação e o devido tratamento destas, proporcionando assim, um sistema eficaz e eficiente.

\section{- Subsistema de pesquisa de marketing}

Um dos propósitos do subsistema de pesquisa de marketing são identificação e satisfação das necessidades do cliente. No entanto, para que as informações sejam filtradas e analisadas, é importante que o subsistema esteja em concordância com os demais subsistemas, para que assim, obtenha dados e compreenda as solicitações dos decisores, 
e desta maneira, possa avaliar as necessidades de informações bem como fornecer aos decisores informações relevantes, precisas, confiáveis e atuais que agilize a tomada de decisão.

Nesse contexto, apresenta-se o bibliotecário como gestor das pesquisas de marketing, com habilidades de aferir dados e coordenar as etapas da pesquisa, que deve enfocar duas demandas: 1) é identificar os problemas e 2) propor soluções para os mesmos. O subsistema de pesquisa de marketing possui seis etapas descritas a seguir:

1‥ Etapa - Definir o problema;

$2^{\circ}$. Etapa - Elaboração de uma Abordagem do Problema;

3‥ Etapa - Concepção da Pesquisa;

40. Etapa - Trabalho de Campo ou Coleta de Dados;

5․ Etapa - Preparação e Análise dos Dados;

6‥ Etapa - Preparação e Apresentação do Relatório.

As necessidades de informação são definidas pelos decisores auxiliados por uma equipe interdisciplinar e são transmitidas ao SIM que delega ao bibliotecário a responsabilidade de realizar a pesquisa de marketing, por meio da coleta, tratamento, processamento e disseminação das informações solicitadas pelos decisores. Essas informações devem proporcionar subsídios à tomada de decisão e definir as metas a serem seguidas para a finalização dos objetivos da organização.

\section{- Subsistema de análise}

A informação é fundamental para o funcionamento dos sistemas e a tecnologia está provocando uma mudança na forma de tratamento, disseminação e uso das informações. As tecnologias da informação (TI) são hoje uma importante ferramenta nos processos de análise da informação; contudo o uso da tecnologia na Análise da Informação é uma atividade interagente, na qual os bibliotecários devem ter os conhecimentos interdisciplinares e espírito de equipe. 
Assim, a informação é de suma importância para as organizações e a efetiva análise dessas informações possibilita a criação de novos produtos e serviços.

Para obtenção de fluxos de informações coerentes e precisos, é imprescindível que a informação esteja correta, acessível, segura e de fácil acesso. Para que isto seja possível, a análise informacional deve estar fundamentada em atividades que analisam, traduzem e representam os conteúdos informacionais para que os gestores "busquem" e recuperem as informações necessárias ao processo de tomada de decisão. É importante identificar a participação de bibliotecários em Sistemas de Informação de Marketing empresarial, visto que este profissional possui habilidades e competências de análise documentária e informacional para participar de uma equipe interdisciplinar para desenvolver um SIM seguro e produtivo.

\section{- Subsistema de tratamento da informação}

A etapa de subsistema de tratamento da informação visa a organizar os dados e informações para que este ofereça suporte às decisões e sejam aplicados aos SIM.

No processo de tratamento e análise da informação, o papel do bibliotecário é extremamente importante, pois como abordado na revisão de literatura, esse profissional têm as habilidades e competências que contribuem com o desenvolvimento do modelo de sistema proposto, portanto, deve estar integrado na equipe interdisciplinar do SIM.

O tratamento técnico da informação utiliza-se de ferramentas e códigos que permitem a padronização dessa atividade, tais como: i) Classificação Decimal universal (CDU); ii) Classificação Decimal de Dewey (CDD); iii) Webdewey; iv) Classificação Decimal de Direito (CDDir); v) Tabela de Cutter; e vi) Código de catalogação Angloamericano. Essas ferramentas foram desenvolvidas e devem ser aplicadas por bibliotecários, pois sua correta utilização propicia a recuperação da informação com rapidez nas decisões, promovendo 
produtos e serviços de forma eficaz e eficiente. Atualmente há outras ferramentas que possibilita o tratamento da informação como, por exemplo: padrões de metadados, resources description and accsses RDA; modelagem de dados; softwares de indexação de imagem digital; MARC21; ferramentas de EAD, entre outras.

\section{- Subsistema de disseminação seletiva da informação (DSI)}

A etapa do DSI visa a identificar os clientes (internos e externos) a quem os serviços serão destinados. Essa identificação é realizada a partir dos objetivos do SIM e da pesquisa de Marketing.

O serviço de DSI tem, ao longo dos anos, se automatizado e esta canalização e desenvolvimento são cada vez mais facilitados por meio da internet. A automatização do subsistema DSI, possui seis etapas, que devem ser desenvolvidas por bibliotecários:

1. Levantamento do perfil de interesse dos clientes - permite a descrição detalhada da qualificação, especialidade, necessidades e interesses dos usuários;

2. Análise e tradução dos perfis - atribuição de descritores, palavras-chave e códigos legíveis pelo sistema, que representam os temas a serem recuperados;

3. Arquivamento dos perfis - armazenamento no sistema dos perfis dos usuários, para processamento automatizado;

4. Recuperação da informação - realizada por computador confronta os perfis dos usuários e sua atualização com a base de dados da organização;

5. Controle de qualidade - verificação realizada para teste dos resultados, a fim de identificar possíveis erros de estratégia e de linguagem;

6. Expedição aos usuários - envio de relatórios e fichas de avaliação, após o resultado do controle de qualidade.

De acordo com o modelo proposto, os subsistemas são correlatos e devem interagir entre si, pois se todas as etapas forem descritas e desenvolvidas de maneira integrada, o sistema proporciona informações com maior rapidez, antecipando-se aos decisores a tomada de decisão na organização. 
Neste contexto, ao integrar uma equipe interdisciplinar 0 bibliotecário torna-se agente da DSI como mediador entre o Sistema e os decisores que possibilita identificar as necessidades de informação, bem como tratar, analisar e disponibilizar as mesmas aos decisores utilizando-se das tecnologias de informação no desenvolvimento do processo.

\section{- Controle e avaliação}

Essa etapa é a última no sistema e tem o objetivo de avaliar todos os processos do SIM e prover a retroalimentação do sistema, cuja finalidade é verificar se os clientes (internos e externos) são atendidos, e, se as informações disponibilizadas estão de acordo com os preceitos de qualidade, que ostente a utilidade, viabilidade, propriedade, precisão e exatidão, atributos estes, mencionados anteriormente.

O papel do controle e da avaliação deve ser desempenhado nas etapas dos subsistemas, para que, a cada etapa, os erros e falhas possam ser verificados e solucionados. O papel do bibliotecário na avaliação e controle é o de documentar e garantir a integridade dos dados e informações, vistoriando cada etapa, para que o processo não tenha falhas, e, desta forma, possibilite a ocorrência de produtos e serviços sem qualquer tipo de distorção, que garanta aos decisores a confiabilidade da informação no momento da tomada de decisão.

As ferramentas de tecnologia de informação são imprescindíveis no desenvolvimento do processo de avaliação, no entanto, a interação humana deve ser mediadora em todo processo proporcionando assim, dados e informação sobre a eficiência do sistema, bem como sua eficácia, para aperfeiçoar o feedback aos clientes e decisores.

Assim, deve-se ter claro que esta etapa de controle e avaliação uma fase cujo objetivo é aprimorar a disponibilização e uso da informação no desenvolvimento do SIM. 


\section{CONSIDERAÇÕES FINAIS}

O objetivo deste artigo foi estudar a integração do bibliotecário em uma equipe interdisciplinar e seu papel como gestor de sistema de informação de marketing em unidades de informação organizacional. Com base em modelos de sistemas de informação de marketing, propôs-se um modelo teórico de sistema de informação de marketing (SIM) para as organizações e verificou-se a inserção de bibliotecários como agentes mediadores do processo.

Para desenvolver o modelo, realizou-se uma revisão da literatura como fundamentação teórica, para identificar as vantagens e desvantagens de modelos existentes e propor um sistema que proporcionasse aos decisores e clientes a informação precisa e acessível, de forma a fundamentar as tomadas de decisão.

Neste contexto, o bibliotecário tem seu papel como gestor do SIM, responsável pelo recolhimento, armazenamento, processamento, recuperação, preservação e disseminação e uso das informações de forma, a agregar valor aos produtos e serviços oferecidos aos decisores.

Constatou-se que a construção de um sistema de informação de marketing precisa ser definida no planejamento estratégico de marketing da organização e que esse processo envolve as seguintes etapas: definição da estrutura do sistema; coleta das informações; recuperação das informações, disseminação e uso da informação; manutenção do sistema; feedback aos clientes e decisores. A cada etapa, é necessário um procedimento sincronizado com a estratégia global da organização que deve estar integrado por uma equipe interdisciplinar definido planejamento estratégico organizacional.

É importante a conscientização, por parte de todos os componentes da equipe do SIM, de que o sistema de informação de marketing é responsável pela concretização dos produtos e serviços definidos nas metas e objetivos da organização, bem como na promoção da satisfação dos clientes (interno e externo). 
O bibliotecário denominado nesse artigo por "Bibliotecário de Sistemas" deve ter habilidades e competências para desenvolver sistemas informacionais, conhecer os fundamentos e técnicas de marketing, bem como ter noções de análise de sistemas, visto que o marketing é importante para identificar e conhecer os clientes potenciais e, a partir desses conhecimentos, desenvolver produtos e serviços que satisfaçam as suas necessidades individuais, utilizando-se de Tecnologias da Informação para o pleno funcionamento.

Como resultado do modelo proposto, definiu-se que um Sistema de Informação de Marketing (SIM) é um processo no qual se monitora, registra, organiza e processa informações sobre o ambiente externo e interno em que a unidade de informação está inserida. Evidenciou-se a presença de bibliotecários com suas habilidades e capacidades de previsão, organização, comando, coordenação e controle de sistemas da informação nas atividades do sistema de informação de marketing.

Demonstrou-se que a comunicação, expressão, demonstração e aproximação dos clientes (internos e externos) são necessárias para manter a integridade do sistema.

Ao finalizar esse artigo, apontou-se a dificuldade do desenvolvimento de um estudo de caso em organizações o que proporcionaria o estudo empírico para a validação do modelo proposto. No entanto, é importante o desenvolvimento da validação do modelo com vistas a obter um recurso a mais no desenvolvimento e aplicação de um Sistema de Informação de Marketing que vise a agilizar o processo de tomada de decisão às organizações.

\section{REFERÊNCIAS}

AMARAL, Sueli Angélica. Marketing da informação: abordagem inovadora para entender o mercado e o negócio da informação. Ciência da Informação, Brasília, v. 40, n. 1, p. 85-98, jan./abr. 2011. Disponível em: <http://www.scielo.br/pdf/ci/v40n1/a07v40n1.pdf>. Acesso em: 6 jul. 2015. 
AMARAL, Sueli Angélica. Marketing e inteligência competitiva: aspectos complementares da gestão da informação e do conhecimento. In:

cap. 1. Marketing na ciência da informação. Brasília: UNB, 2007.

AMERICAN MARKETING ASSOCIATION. Marketing. 2013. Disponível em: <https://www.ama.org/AboutAMA/Pages/Definition-of-

Marketing.aspx>. Acesso em: 6 jul. 2015.

ARRUD, Maria da Conceição Calmon; MARTELETO, Regina Maria; SOUZA, Donaldo Bello. Educação, trabalho e o delineamento de novos perfis profissionais: o bibliotecário em questão. Ciência da Informação, Brasília, v. 29, n. 3, p. 14-24, 2000.

BRASIL. Ministério da Educação. Parecer CNE/CES 492/2001. Disponível em:

<http://portal.mec.gov.br/cne/arquivos/pdf/CES0492.pdf>. Acesso em: 6 jul. 2015.

CUNHA, Miriam Vieira. O profissional da informação e o mercado de trabalho. Revista Informação e Sociedade: Estudos, João Pessoa, v. 10, n. 1, 2000. Disponível em:

$<$ http://www.ies.ufpb.br/ojs2/index.php/ies/article/view/347/269>. Acesso em: 6 jul. 2015.

FERREIRA, Danielle Thiago. Profissional da informação e a gestão do conhecimento: perfil de habilidades demandadas por empresas de recrutamento e seleção de recursos humanos. In: SOUTO, Leonardo Fernandes (Org.). O profissional da informação em tempo de mudança. Campinas: Alínea, 2005. p. 13-27.

INTERNATIONAL SOCIAL MARKETING ASSOCIATION. Social marketing definition. 2013. Disponível em: <http://www.isocialmarketing.org/social-marketing-definition>. Acesso em: 6 jul. 2015.

JAMIL, George Leal. Repensando a TI na empresa moderna: atualizando a gestão com a tecnologia da informação. Rio de Janeiro: Axcel Books, 2001.

KOTLER, Philip; ROBERTO, Eduardo L. Marketing social: estratégias para alterar o comportamento público. Rio de Janeiro: Campus, 1992.

KOTLER, Philip; ARMSTRONG, Gary. Administração de marketing. 10. ed. São Paulo: Pearson Prentice Hall, 2000. 
KOZEL JUNIOR, José. $O$ top do marketing brasileiro. São Paulo:

Scipione, 1997.

LAMBIN, Jean Jacques. Marketing estratégico. Lisboa: McGraw-Hill, 2000.

LI, Eldon Y.; MCLEOD JUNIOR, Raymond; ROGERS, John C.

Marketing information system in fortune 500 companies: a longitudinal analysis of 1980, 1990, and 2000. Information \& Manegement, Amsterdam, v. 38, n. 5, p. 307-322, abr. 2001.

MATTAR, Fauze Najib. Sistemas de informação de marketing. Revista Mercado Global, São Paulo, ano 13, n. 67, p. 24-45, mar./abr. 1986. Disponível em: <http://www.fauze.com.br/htm/Artigos.aspx?ano=1986>. Acesso em: 6 jul. 2015.

MATTAR, Fauze Najib. Pesquisa de marketing: metodologia, planejamento. 3. ed. São Paulo: Atlas, 1996. 2 v.

PIGGOTT, Sylvia. A new paradigm for excellence in information services. 1996. Disponível em:

<http://www.si.umich.edu/cristaled/postings/V41.html>. Acesso em: 7 out. 2009.

REZENDE, Yara. Informação para negócios: os novos agentes do conhecimento e a gestão do capital intelectual. Ciência da Informação, Brasília, v. 31, n. 2, maio/ago. 2002.

SEMENIK, Richard J.; BAMOZZY, Gary J. Princípios de marketing: uma perspectiva global. São Paulo: Makron Books, 1996.

SILVA, Fabiano Couto Corrêa. Bibliotecários especialistas: guia de especialidades e recursos informacionais. Brasília: Thesaurus, 2005.

SILVA, Valéria Bastos et al. Possibilidades de atividades colaborativas e cooperativas entre bibliotecários e gestores da informação em práticas profissionais de armazenamento, organização, fluxo e recuperação da informação. Múltiplos Olhares em Ciência da Informação, Belo Horizonte, v. 3, n. 2, 2013. Disponível em:

$<$ http://portaldeperiodicos.eci.ufmg.br/index.php/moci/article/view/2098/1 300>. Acesso em: 1 jul. 2015.

STAIR, Ralph M.; REYNOLDS, George W. Princípios de sistemas de informação: uma abordagem gerencial. 4. ed. Rio de Janeiro: Livros Técnicos e Científicos, 1999. 


\title{
Title
}

Marketing information systems in units of business information: a proposed model

\begin{abstract}
Introduction: It proposes a theoretical model of marketing information system, which provides qualitiy attributes informations, such as: accuracy, economy, flexibility, reliability, relevance, simplicity and verifiability to the decision-makers of business organizations, based on the systemic vision and marketing theories.

Objective: Present a model of marketing information system for business units, identifying the requirements, skills and abilities that the market demands of the librarian and his or hers integration.

Methodology: Literature review that enabled the theoretic knowledge to propose the model.

Results: The proposed model consists of five stages and constituent of subsystems that were not identified in existing marketing information systems, where it is confirmed that the organization of information is necessary for the development of the organization.

Conclusions: It was identified that the librarian is an active agent, a mediator of information in marketing information systems in business units, must be present at all levels of the process and provide the administrators a greater credibility in the decisions taken.
\end{abstract}

Keywords: Information systems. Librarian-skills and abilities. Marketing information systems.

\section{Titulo}

Sistemas de información en unidades de información empresa de marketing: un modelo propuesto

\section{Resumen}

Introducción: Se propone un modelo teórico del sistema de información de marketing, que proporciona información con atributos cualidades como la precisión, la eficiencia de costes, flexibilidad, fiabilidad, pertinencia, sencillez y decisión verificabilidad los responsables de las organizaciones empresariales, basadas en la opinión de los sistemas y teorías de marketing.

Propósito: Presenta un modelo de sistema de información de marketing para las unidades de negocio, identificando los requisitos, competencias y habilidades que el mercado exige Bibliotecario y la integración.

Metodología: Revisión bibliográfica que permitió a los conocimientos teóricos a proponer el modelo.

Resultados: El modelo propuesto se compone de cinco etapas y un total de subsistemas que no fueron identificadas en los sistemas de información de marketing existentes, lo que confirma que la organización de la información es necesaria para el desarrollo de la organización

Conclusiones: Se identificó que el bibliotecario es un agente activo, agente de información en la comercialización de sistemas de información en las unidades de negocio, deben estar presentes en todos los niveles del proceso y 
Ana Maria Pereira, Carla Campos Pereira

Sistemas de informação de marketing em unidades de informação empresarial: um modelo proposto

proporcionar a los administradores una mayor credibilidad en las decisiones tomadas.

Palabras clave: Sistemas de información. Bibliotecario-destrezas y habilidades. Comercialización de sistemas de información.

Recebido em: 11.03.2014

Aceito em: 31.07.2015 